\title{
Communicating Genetic and Genomic Information: Health Literacy and Numeracy Considerations
}

\author{
D.H. Lea ${ }^{\text {a }} \quad$ K.A. Kaphingst ${ }^{\text {b }}$ D. Bowen ${ }^{\text {c }}$ I. Lipkus ${ }^{\text {d }}$ D.W. Hadley ${ }^{a}$ \\ ${ }^{a}$ National Human Genome Research Institute, NIH, Bethesda, Md., b'Washington University School of Medicine, \\ St. Louis, Mo., 'Boston University, Boston, Mass., and ${ }^{\mathrm{d}}$ Duke University, Durham, N.C., USA
}

\section{Key Words}

Genetic communication - Genomics $\cdot$ Health behavior change $\cdot$ Health literacy $\cdot$ Numeracy

\begin{abstract}
Genomic research is transforming our understanding of the role of genes in health and disease. These advances, and their application to common diseases that affect large segments of the general population, suggest that researchers and practitioners in public health genomics will increasingly be called upon to translate genomic information to individuals with varying levels of health literacy and numeracy. This paper discusses the current state of research regarding public understanding of genetics and genomics, the influence of health literacy and numeracy on genetic communication, and behavioral responses to genetic and genomic information. The existing research suggests that members of the general public have some familiarity with genetic and genomic terms but have gaps in understanding of underlying concepts. Findings from the limited research base to date indicate that health literacy affects understanding of print and oral communications about genetic and genomic information. Numeracy is also likely to be an important predictor of being able to understand and apply this information, al-
\end{abstract}

though little research has been conducted in this area to date. In addition, although some research has examined behavior change in response to the receipt of information about genetic risk for familial disorders and genomic susceptibility to common, complex diseases, the effects of health literacy and numeracy on these responses have not been examined. Potential areas in which additional research is needed are identified and practical suggestions for presenting numeric risk information are outlined. Public health genomics researchers and practitioners are uniquely positioned to engage in research that explores how different audiences react to and use genomic risk information.

Copyright $\odot 2010$ S. Karger AG, Basel

\section{Introduction}

Rapid growth in genetic and genomic research has transformed our understanding of the role of genes in health and disease. The historical focus of genetic research has been on rare, single-gene disorders, such as phenylketonuria, achondroplasia, fragile X syndrome, Duchenne muscular dystrophy, and Huntington disease, in which disease risk is largely based on the presence or absence of a mutation in a single associated gene. This

\section{KARGER}

Fax +41613061234

E-Mail karger@karger.ch

www.karger.com (c) 2010 S. Karger AG, Basel

Accessible online at: www.karger.com/phg
Dale Halsey Lea

National Human Genome Research Institute

31 Center Drive, Bldg 31, Room B1B55

Bethesda, MD 20892-2070 (USA)

Tel. +1 207781 2098, Fax +1 301-480-3066, E-Mail lead@mail.nih.gov 
focus has been greatly expanded in recent years. Research in genomics is now examining the genetic components of common, complex diseases, such as cancer, diabetes, osteoporosis, and heart disease. For these diseases, the contributions of single genes to risk are often small in comparison to the rare, inherited diseases, and disease risk is based on multiple genetic and environmental factors. Such genomic research therefore raises important new issues in communicating with patients and the general public about genetic contributions to disease, both in terms of the content of disease risk messages and the much larger population to which these messages are relevant.

Genetic susceptibility to common, complex disease outcomes is an issue that will be of relevance to most, if not all, individuals. Genes play a role in 9 of the 10 leading causes of death in the United States, including heart disease, cancer and diabetes [1]. Genome-wide association studies have revealed many associations between gene variants and specific disease outcomes, raising the potential of new approaches to prevention and treatment [2]. The findings of these studies also present unique challenges to interpreting and conveying disease risk because they can generally only illuminate part of an individual's risk for a given disease.

With these advances in genetic susceptibility research, public health researchers and practitioners will increasingly be called upon to communicate with the general public about genomics across multiple contexts. Advances in genomics have expanded discussions of genes beyond the traditional settings of maternal and child health programs (e.g. newborn screening) and the specialized genetic counseling sessions to applications for the prevention and treatment of common, adult-onset diseases [3]. In addition, private, for-profit companies have begun advertising directly to the general public about genetic testing. Tests that can screen an individual's genome for gene variants that affect disease risk are increasingly available direct-to-consumer on the Internet and can increasingly reach large segments of the population. Most of these companies do not provide genetic counseling or medical support. It is therefore likely that at least some individuals who undergo such testing will look to health care providers and public health practitioners for assistance with interpretation of results [4].

The effectiveness of strategies to communicate with the general public about genetics and genomics will depend upon individuals' levels of skills and knowledge. Health literacy is therefore a critical issue to consider in the context of genetic communication. Health literacy has been defined as the degree to which individuals can obtain, process, and understand the basic health information and services needed to make appropriate health decisions [5]. As will be described in the sections below, health literacy encompasses multiple domains of skills related to using health information, including print skills, oral communication skills and quantitative skills. A substantial proportion of individuals in the United States have limitations in these skill domains as well as lower levels of background knowledge. An analysis from the 2003 National Assessment of Adult Literacy revealed that about $36 \%$ of U.S. adults have limited health literacy [6]. Individuals with limited health literacy have, on average, increased incidence of chronic illness, lower utilization of preventive health services and poorer self-reported health $[5,7]$.

Reaching individuals with limited health literacy with understandable and usable information about genomics will therefore be critical for disease prevention and treatment approaches targeting populations with the greatest health needs. As noted by Chen and Goodson [8], this will mean addressing issues associated to the public's levels of knowledge and skills related to genetics. This paper provides a review of existing research that can inform these communication issues. We present studies regarding the general public's knowledge of topics related to genetics and genomics, highlighting areas of understanding as well as knowledge gaps in different populations. We discuss the relevance of health literacy and numeracy skills to the communication of genetic and genomic information and summarize the limited existing research to date in these areas. We describe the state of research in behavioral responses to genetic information and discuss the need to integrate health literacy and numeracy considerations into such studies. Finally, we provide recommendations for future research on communicating genetic and genomic information.

\section{Public Understanding of Genetics and Genomics}

Investigation of the public's understanding of genetic terms and concepts is an essential component in the design of effective communication strategies for genetic and genomic information. Research has begun to clarify individuals' perceptions, beliefs and factors that influence understanding [9]. Although this research has not been framed in terms of health literacy to date, existing findings can still shed light on levels of background conceptual knowledge about genetics and genomics in the 
general public and across some population subgroups. This section summarizes major themes in this body of literature and highlights gaps to be addressed in future studies.

In the 1990s, a major theme in the research into the public understanding of the role of genes was exploration of beliefs about causes of birth defects and genetic conditions. For example, Cohen et al. [10] found variability in these beliefs across racial and ethnic groups, with a significant difference in attribution of birth defects to chromosomal causes. They also observed some differences in beliefs based on whether or not the participant had a family history of a birth defect. Although $43 \%$ of participants in this study had no more than a high school degree, differences in beliefs based on educational attainment were not examined. In another study in this area, Lafayette et al. [11] found that most relatives of individuals with cystic fibrosis underestimated their carrier risk and overestimated their risk of having a child with the disease. These researchers found that individuals with lower educational attainment had less knowledge about cystic fibrosis. A qualitative study suggested that adults who had genetic counseling and carrier testing had fairly high knowledge about cystic fibrosis, although the socio-demographic characteristics of the participants were not reported [12]. These findings therefore suggested significant differences across groups in understanding of the role of genes in conditions such as birth defects as well as a potential correlation between education and knowledge about genes.

In more recent public understanding research, studies have focused both on individuals' beliefs about genetic causation for common, complex health conditions and on their understanding of basic genomic concepts. Parrott et al. [13] examined perceptions of the influence of various factors on human traits and common diseases, such as cancer, among 77 focus group participants. Their findings suggested that people did not give genes a primary role in the causation of all human characteristics; they believed that the relative role of genes and other factors varied for different traits. For example, the effect of genes on the causation of breast and prostate cancer was seen as greater than on lung cancer. In this diverse sample, differences in attributions were seen by race, gender, income and having had a biology course in college. Interestingly, the pattern of the results suggested that attributions were specific to different conditions and traits rather than being a global attitude about the role of genes. Other recent research has also suggested that the public generally does not believe that an individual carrying a gene variant will certainly develop an associated health condition. Based on the results of 13 focus groups, Bates et al. [14] found that only about a quarter of participants believed that a person who had a gene for heart disease would certainly get the disease, although perceived risk was somewhat greater among African Americans compared to European Americans. Other qualitative research has probed more deeply into factors affecting this sense of perceived risk. A meta-ethnographic review of qualitative research studies found that individuals' experiences of family members' illnesses and personal models of disease causation influenced their perceived vulnerability. The findings suggested that differences in perceived vulnerability to various health conditions may affect how individuals respond to information about genetic risk [15]. However, the review did not examine differences in perceived vulnerability or understanding of familial risk across population subgroups. These studies, taken together, indicate that the general public does have an understanding of the multifactorial nature of common, complex conditions. Results to date also suggest that personal experiences influence individuals' perceived risk of disease.

In another major theme in research into the public's understanding of genetics and genomics, some studies have focused more specifically on understanding of underlying genetic concepts. In qualitative interviews with 62 adults, Lanie et al. [16] found that participants had a limited understanding of what genes are, how they are inherited and where they are located in the body. However, participants generally believed that they understood information about genes. The authors did not report differences among subgroups, although $68 \%$ of participants had at least some college education. Mesters et al. [17] found similar gaps in and overestimation of understanding among 69 individuals participating in focus groups. In this study, although participants talked about genes and DNA in association with cancer, their understanding of these concepts did not go deeper than word familiarity. Molster et al. [18] examined individuals' understanding of genetic concepts in a cross-sectional telephone survey of 1,009 adults in Western Australia. The findings showed that although most respondents were aware of basic genetic concepts and the connection between genes, inheritance and risk of disease, a significantly lower number of respondents understood the biological mechanisms underlying these connections. Respondents also had misconceptions around the meaning of increased genetic risk. Those with 12 years or more of education, those who were between 18 and 44 years of age, women, those with higher annual household incomes, and those who had 
sought information about genes had higher genetic knowledge. The findings of these studies therefore suggest that members of the general public have some familiarity with terms used in genetics and genomics, but substantial gaps exist in their understanding of the underlying concepts.

Smerecnik et al. [19] have recently added to this literature by describing a framework that can arrange this line of research. The authors conducted a literature review examining current public knowledge of genetic risk factors for multifactorial diseases and found that this knowledge is limited. They proposed a theory-based framework to better understand the public's current knowledge regarding this topic. The framework distinguishes between 3 different types of knowledge of genetic risk factors, namely, awareness knowledge, how-to (practical) knowledge and principles (theoretical) knowledge. The authors describe these forms of knowledge as along a continuum, representing increasingly complex forms of knowledge. This framework therefore has the advantage of allowing researchers to examine how deeply the general public understands concepts.

One additional area within the public understanding of genetics literature has focused on possible influences on understanding, particularly the effects of the mass media. Increasing attention has been paid to new genetic discoveries and genetic tests in the media, in ways that might hype genetic discoveries or present them as threats [20]. Although concerns have been raised that such attention to genetic discoveries might heighten beliefs among the general public of genes as a primary causal factor for common, complex conditions [21], the findings presented above suggest that this has not generally been the case, at least for the majority of individuals. The effects of the mass media on public understanding of genetics and genomics are an important area for additional research.

In summary, research to date regarding the public's understanding of genetics and genomics suggests that individuals do believe that genes play a role in the causation of common, complex diseases. However, they do not seem to believe that genes are the primary causal factor and have a more multifactorial understanding of these diseases. While members of the general public may be familiar with genetics terms, they may have substantial knowledge gaps regarding basic facts about genes and DNA. Individuals may also overestimate their understanding of concepts related to genetics. This research base has a number of substantial limitations to date. Studies have generally been small and qualitative, potentially limiting the generalizability of findings. There is a clear need for additional large quantitative studies examining public understanding in representative population samples with sufficient sample size to examine differences across subgroups. Most notably, studies have not yet examined differences in knowledge or understanding across groups with varying levels of health literacy. These data are critical to developing approaches to communicate about genetics with adults who have limited health literacy. In addition, the impact of differences in knowledge on responses to new genetic information has not been systematically examined, as will be discussed further below.

\section{Health Literacy, Genetics and Genomics}

Health literacy is a critical issue for public health researchers and practitioners to consider as they develop ways to communicate genetic and genomic information to the general public. Across a wide range of health topics, it has been found that the level of skills required to understand and use health information is often higher than that of the intended audience $[5,22]$. Although this has not been systematically examined in the area of genetics, adults with limited health literacy are likely to face substantial challenges in understanding and using genetic and genomic information [23]. As mentioned above, a substantial proportion of U.S. adults (about 36\%) have limited health literacy [6]. It is also important to note that the burden of limited health literacy is not equally distributed across the U.S. adult population. Among racial and ethnic groups, Hispanic, Black and American Indian/Alaska Native adults have lower health literacy, on average, compared to White or Asian/Pacific Islander adults [6]. Further, adults with limited educational attainment, those who live in poverty and those who are older have lower average health literacy [6]. Limited health literacy is therefore likely to pose a particular challenge to communicating with underserved communities about genetics and genomics.

\section{Research on Genetics, Genomics and Health Literacy}

Relatively little research has been done to date in the area of health literacy and genetics and genomics. It is likely, however, that these content topics will pose difficulties across all domains of health literacy. The Institute of Medicine has operationalized health literacy as having the following components: oral literacy (listening and speaking skills), print literacy (reading and writing skills), and numeracy (basic quantitative skills), in addition to 
cultural and conceptual knowledge [5]. Taking each of these domains in turn, having adequate oral literacy skills is likely to be important in a number of verbal communication contexts in genetics and genomics. For example, individuals with limited oral literacy skills might understand less of genetic information communicated by health care providers and also might be less able to ask questions in such encounters. Those with limited print literacy skills might be less able to use a variety of potential written informational sources about genetics and genomics, including educational brochures, newspapers, and the Internet. The use of technical and medical jargon in genetic and genomic information may pose difficulties in both the oral and print domains. With respect to numeracy, the often probabilistic information that is a part of communication about genetics and genomics will likely require higher levels of numeracy skills, as will be addressed in the next section. Finally, with respect to knowledge, many unfamiliar and abstract concepts may be important for understanding new information about genetics and genomics [17]. Some of these concepts were discussed above, such as inheritance, genetic variation or multifactorial causation. Individuals with limited health literacy may therefore have more difficulty with genetic and genomic information due to both lower levels of conceptual knowledge and lower levels of skills.

This next section will discuss the few studies that have been conducted to date to examine the effects of print and oral literacy on communication about genetics and genomics. Thompson et al. [24] conducted formative research to develop a print brochure to describe BRCA1/2 testing to an audience with limited literacy. Although their brochure was generally favorably received, there were remaining problems with comprehension of the terminology and figures. In a study conducted with 163 stage I/II breast cancer patients, Lillie et al. [25] found that individuals with lower health literacy recalled less information about a genomic test that identified recurrence risk and had less preference for active decisionmaking about the test. The measure of health literacy used in this study was the Rapid Estimate of Adult Learning in Medicine, a commonly used and validated measure that is a word recognition and pronunciation test [26]. Recently, Erby et al. [27] developed and validated a similar measure specific to the context of genetics called the Rapid Estimate of Adult Literacy in Genetics (REAL-G). They showed that individuals with lower scores on the REAL-G, reflecting lower genetic literacy, had lower knowledge scores after viewing videotaped genetic counseling sessions. One other study has systematically exam-

Communicating Genetic Information ined the oral literacy demands of genetic counseling. This study showed that, among simulated clients, more difficult oral language was associated with less satisfaction [28].

In summary, the limited existing literature in this area does suggest that health literacy considerations will be critical in developing strategies for communicating with the general public about genetic and genomic risk, particularly for underserved communities. Studies in the domains of print and oral literacy have indicated that individuals with limited health literacy may understand less of these written and verbal messages and may also be less able to engage in discussions with health care providers about genetic information. However, the research base in this area is still quite limited. In particular, there is a pressing need for research investigating how health literacy affects individuals' understanding of information about genomic susceptibility to common, complex disease outcomes. The development of effective strategies for communicating genetic and genomic information that are appropriate for individuals with a range of health literacy levels will likely require bringing together researchers from diverse fields such as adult learning, education, public health, and health services.

\section{Applying the Science of Numeracy to Communicating Genetic and Genomic Risk}

As discussed in the previous section, numeracy, a component of health literacy, is likely to be critical in conveying numerical information about genetics and genomics. Health numeracy, which relates to individuals' skills with mathematical concepts and their applications, is increasingly recognized as important in all medical decision-making and risk communication, including the domains of genetics and genomics. To date, there is almost no research that directly has investigated numeracy and genetics and genomics. Therefore, this section addresses practical applications of numeracy in communicating about genetics and genomics based on risk communication research conducted in other health domains.

Health numeracy is defined as 'the degree to which individuals have the capacity to access, process, interpret, communicate, and act on numerical, quantitative, graphical, biostatistical, probabilistic health information needed to make effective health decisions' [29, p. 375]. This definition encompasses both individuals' capacities with the form of information (e.g. graphic, decimals, fractions) and how they process and interpret numeric information. 
Table 1. Six functions of numeracy in health decisions [33, 63-67]

1 Numeracy facilitates computation. This function refers to the specific skills a person needs to perform mathematical operations, including knowing how and what information to seek to conduct these operations.

2 Numeracy encourages more information seeking and greater depth of processing. This function of numeracy involves the person's motivation to attend to and seek numerical health information.

3 Numeracy improves interpretation of the meaning of provided numbers. This aspect of numeracy refers to a person's ability to make sense of numerical information in order to reach a decision or solution.

4 Numeracy facilitates assessments of likelihood and value. Individuals who are less numerate may have difficulties understanding a question about probabilities, making use of response options or providing a numerical estimate to answer an open-ended question.

5 Numeracy increases acceptance of numerical data. This aspect of numeracy involves whether the recipient accepts as valid the process contributing to the production of quantitative information and/or the conclusions reached from it.

6 Numeracy can promote behavioral change. This dimension implies that numeracy may affect a person's motivation to take action and engage in behaviors based on quantitative information. A person's level of numeracy may either increase or decrease the likelihood of his/her taking action following some quantitative message.

The use of numbers is critical to interactions in the healthcare setting. Health care providers frequently give quantitative information about potential outcomes of preventive behaviors, about the risks and benefits of undergoing medical procedures and about disease risks. Researchers and practitioners have generally assumed that individuals understand such numericinformation. When it is used 'correctly', this information will lead to more informed medical decisions and health behaviors.

These assumptions, however, are now being questioned. Researchers have argued that the logic of mental arithmetic presents significant difficulties for the human brain [30]. Furthermore, not all individuals are equally able to understand and apply numeric information [31]. The 2003 National Assessment of Adult Literacy found that only $13 \%$ of U.S. adults were proficient in quantitative literacy (i.e. numeracy), while $22 \%$ had below basic quantitative literacy and a third had basic quantitative literacy skills [32]. As with health literacy more generally, underserved populations had lower numeracy skills on average. Hispanic adults had the lowest proficiency in quantitative literacy, with $50 \%$ having below basic skill levels compared to $13 \%$ of Whites, $19 \%$ of Asian/Pacific Islanders, and $47 \%$ of Blacks [32].

Numeracy is important because it can influence how and what information is processed and understood in decision-making $[29,33,34]$. Numeracy, therefore, has great relevance to the communication of genetic and genomic risk. Current research and theory describe 6 separate functions of numeracy that could affect health decisionmaking in the context of genetics and genomics, as delineated in table 1. Researchers and practitioners in public health genomics will need to have an understanding of the concepts and 6 functional values of numeracy and how these will affect differences in interpretation of genetic and genomic risk.

\section{Numeracy Considerations in Presenting Genetic and Genomic Risk Information}

Knowing an individual's numeracy may be an important first step in conveying numeric information about genetics and genomics. For example, this knowledge could influence the channel and format used to communicate quantitative information. This section will discuss several broad issues that researchers and practitioners in public health genomics should consider when presenting numeric risk information. First, information providers need to select the specific domains of risk to be discussed, such as risk factors, probabilities of event occurrence (e.g. absolute risk, relative risk), consequences of disease (e.g. social, physiological, psychological), and methods of prevention, if applicable [35]. Second, public health genomics practitioners should give attention to selecting communication formats to be utilized and considering the strengths and weaknesses of different formats. Important questions to consider in this regard include, 'Will the information be communicated numerically, verbally and/ or graphically?' and 'Will the information be framed as gains or losses?'. A recent review paper by Lipkus [36] discussed several strategies for displaying quantitative information that can be applied to this content domain. Third, practitioners need to consider individuals' biases in perception of and personalization of risk. For example, do individuals review and process messages in a biased manner, such as paying selective attention to certain information so that they can limit potential deleterious effects? Existing research suggests that an anchoring-andadjustment bias may occur in the context of genetic risk information, such that individuals insufficiently adjust 
their subjective risk perceptions to the objective information they receive from health care providers [37]. However, more direct empirical research is needed to explore such biases in the context of genetic and genomic risk. Fourth, it is important to probe for understanding of the genetic risk message, particularly for individuals who may have limited health literacy or numeracy. Fifth, the efficacy of risk communications should be evaluated. As an example, if an individual gains greater factual knowledge but without accompanying recommended behavior changes, is the genetic and genomic risk communication a success, failure or neither?

While risk is a difficult concept to convey and one that is not well understood by the general public, genetic and genomic risk communication is expected to increase dramatically in the future. An important challenge facing those who will be at the forefront of communicating genetic and genomic risk is their ability to design health messages that take into consideration the multiple issues related to numeracy outlined above. Prior research on the presentation of numeric risk information more generally can be examined for guidance [38]. These issues clearly need more research, such as studies examining individuals' responses to different formats and presentations of genetic and genomic information. In addition, research is needed to examine the intersection of conceptual knowledge, print and oral literacy and numeracy in the context of genetics and genomics and how these domains influence behavioral responses to information about risk.

\section{Future Directions: Genomic Information, Health Literacy and Behavior Change}

In addition to the challenges involved in communicating genetic and genomic information so that it is understandable, there are additional challenges in providing such information so that it motivates health behavior change. Ideally, genomic susceptibility information would allow focused screening or medical management in individuals identified as being at increased risk. Individuals not at elevated risk could then follow health and medical recommendations given for the general population. No research to date has examined whether providing genetic or genomic information to individuals with limited health literacy or numeracy affects health behavior change. These variables are critical to investigate, as they are potentially modifiable with educational interventions. This section will therefore summarize 2 areas of existing research regarding whether genetic testing leads individuals to change their health behaviors and will then suggest future directions for research related to health literacy.

\section{Genetic Testing and Behavior Change in the Context}

\section{of Familial Conditions}

One body of research on health behavior change following receipt of genetic risk information has examined cancer screening utilization and prophylactic surgical interventions among individuals from families with hereditary cancer syndromes [39]. It is important to note that in these studies, genetic risk information is almost always provided in the context of comprehensive genetic counseling by a trained genetic counselor. The evidence related to hereditary breast and ovarian cancer has suggested that mammography usage in women often increases following the identification of a disease-causing mutation in the genes BRCA1/2 but remains suboptimal [ $40-$ $45]$. The rate of oophorectomy also increases among mutation carriers following genetic testing [46]. In the context of hereditary nonpolyposis colorectal cancer, research has shown that genetic counseling and testing does influence the use of screening procedures and adherence with screening recommendations [47-49]. Heshka et al. [50] conducted a literature review to examine the effects of genetic testing for colorectal carcinoma, hereditary breast and ovarian cancer, and Alzheimer disease on individuals. Behavioral impacts assessed included screening and surveillance behaviors such as mammography, breast exams, colonoscopy, prophylactic surgery, and other preventive behaviors such as diet and exercise. Although mutation carriers generally increased their screening behavior, the change in behavior was less than expected.

Research on health behavior change following genetic testing for familial conditions other than hereditary cancer syndromes has been quite limited. In one study, the identification of mutations for familial hypercholesterolemia had no impact on adherence to cholesterol-lowering behaviors compared to persons clinically diagnosed without genetic testing for the condition [51]. Similarly, in a study of genetic testing for alpha-1-antitrypsin, knowledge of having severe alpha-1-antitrypsin enzyme deficiency, rather than mutation carrier status, resulted in greater use of pharmacotherapy for smoking cessation and greater reduction in smoking compared to those with mild or normal enzyme levels [52].

The literature related to health behavior change following genetic testing for familial genetic conditions therefore suggests that genetic information might lead to 
some changes in screening and other preventive behaviors. However, it is unclear in some contexts whether this is due to the genetic information or diagnosis with a disorder. In addition, screening and surveillance following genetic testing often remain suboptimal. Importantly, most of the participants in these studies have been White and highly educated, although socio-demographic characteristics are not consistently reported. No studies have examined differences in behavior change across such population subgroups, and none of the studies have measured health literacy or numeracy. These are important areas for future research to advance the body of knowledge in this field.

\section{Genetic Susceptibility Feedback and Behavior Change}

A second domain in which behavior change following the receipt of genetic information has been examined is in the context of genetic susceptibility for common, complex diseases. The provision of such genetic risk information has been hypothesized to increase motivation to change behavior by increasing risk perception [53], but existing studies have found limited evidence for longterm behavior change. For example, investigations of smoking cessation following receipt of genetic test feedback for lung cancer risk have shown that, although genetic risk information can affect mediators of behavior change (e.g. perceived risk), this information does not generally lead to long-term change in smoking behavior $[52,54-56]$. Ito et al. [57] did find that feedback of genetic information regarding a tobacco-related cancer risk biomarker led to a tendency toward smoking cessation at 9-month follow-up among participants who did not have cancer, with a significant effect among women. However, reviews of the effects of providing biological feedback, using both genetic and non-genetic markers, on smoking cessation have shown that there is no evidence that receiving biological risk factor feedback produced greater behavior change than generic feedback $[58,59]$. Therefore, prior research related to providing genetic susceptibility feedback has generally not shown substantial effects on long-term behavior change. More research, however, is needed in this area as genomic testing for common, complex diseases becomes increasingly available.

The existing body of literature is quite limited in scope in terms of health conditions examined and populations included in research. With rare exceptions [60], individuals' understanding of provided information has not been systematically investigated. Importantly, the effects of health literacy and numeracy on health behavior change following the receipt of genetic and genomic information have not been examined, and this is a critical area for research. Additional factors could also result in variations in health behavior change following the receipt of genetic and genomic test results, such as personal and family experiences with disease, availability and efficacy of preventive and treatment options, and known mediators of health behavior change more generally (e.g. affect, risk perception). More research is certainly needed to understand how learning about genetic or genomic risk might or might not affect a person's behavior, when and under what conditions.

\section{Recommendations for Public Health Genomics Research}

This review has summarized the existing state of the literature regarding public understanding of genetics, health literacy, numeracy, and behavior change in the context of genetics and genomics. Major gaps in this literature have been identified, suggesting numerous areas for future research. Although some literature exists in the area of public understanding of genetics and genomics, larger quantitative studies are needed. In addition, very little is known about understanding among individuals with limited health literacy and numeracy, and this is a critical area for research. Such findings are central to identifying groups that might need more focused educational efforts on genetics and genomics.

Very little research has been conducted to examine how print literacy and oral literacy skills might affect individuals' understanding of genetic and genomic information. Future studies could examine how individuals with limited health literacy understand and use genomic information presented in verbal and print channels. In addition, almost no research has investigated how individuals' numeracy skills impact their interpretation of genetic and genomic information. Studies that examine individuals' responses to different presentations and formats of genetic and genomic information are needed. This type of research will aid in the development of effective strategies for communicating genetic and genomic information that are appropriate for individuals with a range of health literacy levels.

Finally, future research is needed that examines how the domains of print literacy, oral literacy, numeracy, and conceptual knowledge interact in affecting individuals' responses to genetic and genomic information. Studies could also investigate whether health literacy modifies the impact of genetic and genomic information on health 
behavior change. Such research will help to clarify whether and how this information impacts individuals' behaviors. Social and behavioral researchers are just beginning to examine these questions, such as through studies investigating individuals' understanding of and responses to receiving a panel of genetic markers for multiple common diseases [61]. The unique challenges of conveying disease risk based on multiple genetic markers that slightly elevate an individual's risk for common diseases such as diabetes, heart disease and cancer remain to be explored in greater detail.

\section{Conclusions}

Genomic research is leading to increasing availability and use of genetic tests to screen, diagnose and treat disease. These advances will likely mean that public health genomics researchers and practitioners will increasingly be called upon to translate genomic information to the general public. Existing research suggests that the public has gaps in knowledge concerning genetic and genomic concepts. In addition, health literacy and numeracy will likely be important predictors of being able to understand and apply genetic information to improve health. Limited research exists regarding behavior change in response to the receipt of genetic and genomic risk information, and there is as of yet no research focusing on how individuals' health literacy and numeracy affect their responses.

Research advances in genomics will mean increasingly complex communication issues. Public health researchers and practitioners will be uniquely poised to engage in research that explores risk communication strategies involving the use of genomic information that are intended for the general public, as well as to take a leading role in research regarding how communities react to and use genomic risk information both in the short and long term $[53,62]$. Such research is critical to translating the advances of genomic research to improvements in the public's health.

\section{Acknowledgement}

This research was supported by the Intramural Research Program of the National Human Genome Research Institute, National Institutes of Health.

\section{References}

1 National Human Genome Research Institute: Frequently asked questions about genetic and genomic science. 2009. Available at http://www.genome.gov/19016904.

-2 Pearson TA, Manolio TA: How to interpret a genome-wide association study. JAMA 2008; 299:1335-1344.

3 Wang G, Watts G: The role of genetics in the provision of essential public health services. Am J Public Health 2007;97:620-625.

4 Hunter DJ, Khoury MJ, Drazen JM: Letting the genome out of the bottle - will we get our wish? New Engl J Med 2008;358:105-107.

5 Nielsen-Bohlman L, Panzer AM, Kindig DA (eds): Health Literacy: A Prescription to End Confusion. Washington, National Academies Press, 2004.

6 Kutner M, Greenberg E, Jin Y, Paulsen C: The health literacy of America's adults: results from the 2003 National Assessment of Adult Literacy. Washington, National Center for Education Statistics. 2006. Available at http://nces.ed.gov/pubs2006/2006483_1. pdf.

7 Berkman N, Pignone MP, DeWalt D, Sheridan S (eds): Health Literacy: Impact on Health Outcomes. Rockville, MD, Agency for Healthcare Research and Quality, 2004.
8 Chen LS, Goodson P: Public health genomics knowledge and attitudes: a survey of public health educators in the United States. Genet Med 2007;9:496-503.

$\checkmark 9$ Wang C, Bowen DJ, Kardia SL: Research and practice opportunities at the intersection of health education, health behavior, and genomics. Health Educ Behav 2005;32:686701.

10 Cohen LH, Fine BA, Pergament E: An assessment of ethnocultural beliefs regarding the cause of birth defects and genetic disorders. J Genet Couns 1998;50:15-29.

11 Lafayette D, Abuelo D, Passero MA, Tantravahi U: Attitudes toward cystic fibrosis carrier and prenatal testing and utilization of carrier testing among relatives of individuals with cystic fibrosis. J Genet Couns 1998;8: 17-36.

12 Callanan NP, Bloom D, Sorenson JR, DeVellis BM, Cheuvront B: CF carrier testing: experience of relatives. J Genet Couns 1995;4: 83-95.

13 Parrott RL, Silk KJ, Condit C: Diversity in lay perceptions of the sources of human traits: genes, environments, and personal behaviors. Soc Sci Med 2003;56:1099-1109.
14 Bates BR, Templeton A, Achter PJ, Harris TM, Condit CM: What does 'a gene for heart disease' mean? A focus group study of public understanding of genetic risk factors. Am J Med Genet A 2003;119A:156-161.

15 Walter FM, Emery J, Braithwaite D, Marteau TM: Lay understanding of familial risk of common chronic disease: a systematic review and synthesis of qualitative research. Ann Fam Med 2004;2:583-594.

16 Lanie AD, Jayaratne TE, Sheldon JP, Kardia SL, Anderson ES, Feldbaum M, Petty EM: Exploring the public understanding of basic genetic concepts. J Genet Couns 2004;13: 305-320.

17 Mesters I, Ausems A, DeVries H: General public's knowledge, interest and information needs related to genetic cancer: an exploratory study. Eur J Cancer Prev 2005;14:69-75.

18 Molster C, Charles T, Samanek A, O’Leary P: Australian study on public knowledge of genetics and health. Public Health Genomics 2009;12:84-91.

19 Smerecnik CM, Mesters I, de Vries NK, de Vries H: Educating the general public about multifactorial genetic disease: applying a theory-based framework to understand current public knowledge. Genet Med 2008;10 251-258. 
20 Condit C: How culture and science make race 'genetic': motives and strategies for discrete categorization of the continuous and heterogeneous. Lit Med 2007;26:240-268.

$\checkmark 21$ Condit CM, Ofulue N, Sheedy M: Determinism and mass-media portrayals of genetics. Am J Hum Genet 1998;62:979-984.

22 Rudd RE, Moyekens BA, Colton T: Health and literacy: a review of medical and public health literature; in Comings J, Garner B, Smith C (eds): Annual Review of Adult Learning and Literacy. San Francisco, Jossey-Bass, 1999, vol 1, pp 158-199.

23 Johnson JD, Case DO, Andrews JE, Allard SL: Genomics - The perfect informationseeking research problem. J Health Commun 2005;10:323-329.

-24 Thompson HS, Whal E, Fatone A, Brown K, Kwate NO, Valdimarsdottir H: Enhancing the readability of materials describing genetic risk for breast cancer. Cancer Control 2004;11:245-253.

-25 Lillie SE, Brewer NT, O’Neill SC, Morrill E, Dees EC, Carey LA, Rimer B: Retention and use of breast cancer recurrence risk information from genomic tests: the role of health literacy. Cancer Epidemiol Biomarkers Prev 2007;16:249-255.

-26 Davis TC, Long SW, Jackson RH, Mayeaux EJ, George RB, Murphy PW, Crouch MA: Rapid Estimate of Adult Literacy in Medicine: a shortened screening instrument. Fam Med 1993;25:391-395.

27 Erby LH, Roter D, Larson S, Cho J: The rapid estimate of adult literacy in genetics (REAL$\mathrm{G})$ : a means to assess literacy deficits in the context of genetics. Am J Med Genet A 2008; 146A:174-181.

-28 Roter DL, Erby LH, Larson S, Ellington E: Assessing oral literacy demand in genetic counseling dialogue: preliminary test of a conceptual framework. Soc Sci Med 2007; 65:1442-1457.

-29 Goldbeck AL, Ahlers-Smith CR, Paschal AM: A definition and operational framework for health numeracy. Am J Prev Med 2005;29:375-376.

30 Dehaene S: The Number Sense: How the Mind Creates Mathematics. Oxford, Oxford University Press, 1997.

-31 Reyna V, Brainerd C: Numeracy, ratio bias and denominator neglect in judgments of risk and probability. Learn Individ Differ 2008;18:89-107.

32 National Center for Education Statistics: $\mathrm{Na}$ tional Assessment of Adult Literacy (NAAL): A first look at the literacy of America's adults in the 21st century. Washington, U.S. Department of Education. 2006. Available at http://nces.ed.gov/NAAL/PDF/2006470. pdf.

33 Ancker J, Kaufman D: Rethinking health numeracy: a multidisciplinary literature review. J Am Med Inform Assoc 2007;14:713721.
34 Fagerlin A, Ubel PA, Smith DM, ZikmundFisher BJ: Making numbers matter: present and future research in risk communication. Am J Health Behav 2007;31(suppl 1):47-56.

35 Weinstein ND: What does it mean to understand a risk? Evaluating risk comprehension. J Natl Cancer Inst Monogr 1999;25:15-20.

36 Lipkus IM: Numeric, verbal, and visual formats of conveying health risks: suggested best practices and future recommendations. Med Decis Making 2007;27:696-713.

- 37 Senay I, Kaphingst KA: Anchoring-and-adjustment bias in communication of disease risk. Med Decis Making 2009;29:193-201.

38 Peters E, Hibbard J, Slovic P, Dieckmann N: Numeracy skills and the communication, comprehension, and use of risk-benefit information. Health Aff (Millwood) 2007;26: 741-748.

39 Kaphingst KA, McBride CM: Patient responses to genetic information: studies of patients with hereditary cancer syndromes identify issues for use of genetic testing in nephrology practice. Semin Nephrol 2010; 30:203-214.

40 Botkin JR, Smith KR, Croyle RT, Baty BJ, Wylie JE, Dutson D, Chan A, Hamann HA, Lerman C, McDonald J, Venne V, Ward JH, Lyon E: Genetic testing for a BRCA1 mutation, prophylactic surgery and screening behavior in women 2 years post testing. Am J Med Genet 2003;118:201-209.

-41 Claes E, Evers-Kiebooms G, Decruyenaere M, Denayer L, Boogaerts A, Philippe K, Legius E: Surveillance behavior and prophylactic surgery after predictive testing for hereditary breast/ovarian cancer. Behav Med 2005;31:93-105.

42 Lerman C, Hughes C, Croyle RT, Main D, Durham C, Snyder C, Bonney A, Lynch JF, Narod SA, Lynch HT: Prophylactic surgery decisions and 507 surveillance practices one year following BRCA1/2 testing. Prev Med 2000;31:75-80.

43 Loader S, Shields CG, Rowley PT: Impact of genetic testing for breast-ovarian cancer susceptibility. Genet Test 2004;8:1-12.

44 Peshkin BN, Schwartz MD, Isaacs C, Hughes C, Main D, Lerman C: Utilization of breast cancer screening in a clinically based sample of women after BRCA1/2 testing. Cancer Epidemiol Biomarkers Prev 2002;11:11151118.

45 Scheuer L, Kauff N, Robson M, Kelly B, Barakat R, Satagopan J, Ellis N, Hensley M, Boyd J, Borgen P, Norton L, Offit K: Outcome of preventive surgery and screening for breast and ovarian cancer in BRCA mutation carriers. J Clin Oncol 2002;20:1260-1268.

- 46 Schwartz MD, Kaufman E, Peshkin BN, Isaacs D, Hughes C, Demarco T, Finch C, Lerman C: Bilateral prophylactic oophorectomy and ovarian cancer screening following $B R C A 1 / B R C A 2$ mutation testing. J Clin Oncol 2003;21:4034-4041.
47 Collins V, Meiser B, Gaff C, St John DJ, Halliday J: Screening and preventive behaviors one year after predictive genetic testing for hereditary nonpolyposis colorectal carcinoma. Cancer 2005;104:273-281.

48 Hadley DW, Jenkins JF, Dimond E, de Carvalho M, Kirsch I, Palmer CG: Colon cancer screening practices after genetic counseling and testing for hereditary nonpolyposis colorectal cancer. J Clin Oncol 2004;22:3944.

49 Hadley DW, Jenkins JF, Steinberg SM, Liewehr D, Moller S, Martin JC, Calzone KA, Soballe PW, Kirsch IR: Perceptions of cancer risks and predictors of colon and endometrial cancer screening in women undergoing genetic testing for Lynch syndrome. J Clin Oncol 2008;26:948-954

-50 Heshka JT, Palleschi C, Howley H, Wilson B, Wells PS: A systematic review of perceived risks, psychological and behavioral impacts of genetic testing. Genet Med 2008;10:19-32.

-51 Marteau T, Senior V, Humphries SE, Bobrow M, Cranston T, Crook MA, Day L, Fernandez M, Horne R, Iversen A, Jackson Z, Lynas J, Middleton-Price H, Savine R, Sikorski J, Watson M, Weinman J, Wierzbicki AS, Wray R: Genetic risk assessment for FH Trial Study Group: Psychological impact of genetic testing for familial hypercholesterolemia within a previously aware population: a randomized controlled trial. Am J Med Genet A 2004; 128A:285-293.

52 Carpenter MJ, Strange C, Jones Y, Dickson MR, Carter C, Moseley MA, Gilbert GE: Does genetic testing result in behavioral health change? Changes in smoking behavior following testing for alpha-1 antitrypsin deficiency. Ann Behav Med 2007;33:2-28.

53 Marteau TM, Lerman C: Genetic risk and behavioural change. Br Med J 2001;322: 1005-1006.

54 Lerman CE, Schnoll RA, Munafò M: Genetics and smoking cessation improving outcomes in smokers at risk. Am J Prev Med 1997;33(suppl 6):398-405.

- 55 Audrain J, Boyd NR, Roth J, Main D, Caporaso NF, Lerman C: Genetic susceptibility testing in smoking-cessation treatment: oneyear outcomes of a randomized trial. Addict Behav 1997;22:741-751.

56 McBride CM, Bepler G, Lipkus IM, Lyna P, Samsa G, Albright J, Santanu D, Rimer BK: Incorporating genetic susceptibility feedback into a smoking cessation program for African-American smokers with low income. Cancer Epidemiol Biomarkers Prev 2002;11:521-528.

- 57 Ito H, Keitaro M, Kenji W, Toshiko S, Hiroshi K, Katashi O, Kazuo T, Nobuyuki H: An intervention study of smoking cessation with feedback on genetic cancer susceptibility in Japan. Prev Med 2006;42:102-108.

58 McClure JB: Are biomarkers a useful aid in smoking cessation? A review and analysis of the literature. Behav Med 2001;27:37-47. 
59 McClure JB, Westbrook E, Curry SJ, Wetter DW: Proactive, motivationally enhanced smoking cessation counseling among women with elevated cervical cancer risk. Nicotine Tob Res 2005;7:881-889.

60 Lipkus IM, McBride CM, Bepler G, Pollak KI, Lyna P: Interpretation of genetic risk feedback among African American smokers with low socioeconomic status. Health Psychol 2004;23:178-188.

-61 McBride CM, Alford SH, Reid RJ, Larson EB, Baxevanis AD, Brody LC: Putting science over supposition in the arena of personalized genomics. Nat Genet 2008;40:939-941.
62 Hay JL, Meischke HW, Bowen DJ, Mayer J, Shoveller J, Press N, Asgari M, Berwick M, Burke W: Anticipating dissemination of cancer genomics in public health: a theoretical approach to psychosocial and behavioral challenges. Ann Behav Med 2007;34:275286.

63 Estrada CA, Martin-Hryniewicz M, Peek BT, Collins C, Byrd JC: Literacy and numeracy skills and anticoagulant control. Am J Med Sci 2004;328:88-93.

64 Gurmankin AD, Baron J, Armstrong K: The effect of numerical statements of risk on trust and comfort with hypothetical physician risk communication. Med Decis Making 2004;24:265-271.
65 Hibbard JH, Peters E, Dixon A, Tusler M: Consumer competencies and the use of comparative quality information. Med Care Res Rev 2007;64:379-394.

-66 Lipkus IM, Peters E: Understanding the role of numeracy in health: proposed theoretical framework and practical insights. Health Educ Behav 2009;36:1065-1081

67 Peters E, Hibbard J, Slovic P, Dieckmann N: Numeracy skill and the communication, comprehension, and use of risk-benefit information. Health Aff (Millwood) 2007;26: 741-748. 